\title{
Method to Calculate Mining-Induced Fracture Based on the Movement and Deformation of Overburden Strata
}

\author{
Guo-sheng Xu $\mathbb{D},{ }^{1}$ Hui-gui Li $\mathbb{D},{ }^{1}$ De-hai Li $\mathbb{D},{ }^{2}$ and Yan-bin Zhang $\mathbb{D}^{3}$ \\ ${ }^{1}$ College of Mining Engineering, Guizhou University of Engineering Science, Bijie 551700, China \\ ${ }^{2}$ Ming Research Institute, Henan Polytechnic University, Jiaozuo 454000, China \\ ${ }^{3}$ College of Continuing Education, Henan Polytechnic University, Jiaozuo 454000, China \\ Correspondence should be addressed to Guo-sheng Xu; jzxgsheng@126.com
}

Received 30 March 2021; Accepted 20 August 2021; Published 17 September 2021

Academic Editor: Chengwei Fei

Copyright (c) 2021 Guo-sheng Xu et al. This is an open access article distributed under the Creative Commons Attribution License, which permits unrestricted use, distribution, and reproduction in any medium, provided the original work is properly cited.

Mining-induced fracture of overburden strata is intimately related to underground water disasters in coal mining. In this work, we develop an analytical model that uses the probability integral method to calculate the subsidence of the subsurface and the overburden strata. In the developed model, according to the failure characteristics of the mining-induced strata, the horizontal deformation of the strata is expressed by the tensile rate of the elastic plate's neutral plane to reflect the degree of fracture initiation and expansion. The distribution of the water-flowing fractured zone (WFZ) in the overburden strata is calculated by substituting the probability integral function of overburden strata movement into the equation of layer tensile rate. The panel 31071 in Peigou coal mine is taken as a case study, and the height of the water-flowing fractured zone $\left(H_{\mathrm{WFZ}}\right)$ is determined by the proposed method. Conventional empirical methods and the proposed method are used to predict $H_{\mathrm{WFZ}}$ in panels with mining schemes, and the results show that the model is particularly advantageous for inclined coal seam mining where the inclined mining size gradually increases and the coal seam burial depth gradually decreases. In such kind of situations, the overburden strata movement and deformation intensify and the mining fracture develops further with the progress of mining, a feature considered poorly by conventional empirical methods but well represented in the proposed method.

\section{Introduction}

Mining-induced fracture is a key concern in coal mine safety hazards [1-3] such as water and sand inrush, gas outburst, or gas explosion due to gas accumulation in the goaf, or industrial practices (e.g., water-preserving coal mining) that aim to protect the surface ecological environment [4]. Researchers have developed different methods to determine the distribution of the water-flowing fractured zone (WFZ) and calculate the height of the water-flowing fractured zone $\left(H_{\mathrm{WFZ}}\right)$. It is most straightforward and effective to conduct field tests to determine $H_{\mathrm{WFZ}}$ through field test methods (e.g., drilling flushing fluid and double end water plugging $[5,6])$ or geophysical exploration methods (e.g., ultrasonic imaging and parallel network electrical CT) [7]. Nevertheless, field tests and geophysical exploration can be limited when conditions are adverse, when time or money costs are too high for operations or when monitoring is difficult for data collection. Empirical methods can be used for those challenging situations as they avoid experiments in the field. Empirical methods establish a nonlinear statistical relationship by multiple regression analysis between $H_{\mathrm{WFZ}}$ and mining operation variables such as roof lithology, goaf size, coal seam burial depth, and the speed of mining face advancement [8-10]. Their prediction result is more accurate when more data are available about $H_{\mathrm{WFZ}}$. However, because of complexities of the rock mass structure, the mining conditions, and the geological conditions, the prediction formula may give calculation results that are not completely consistent with the actual situation. Some researchers believe that the evolution of water-flowing fractured zone (WFZ) caused by coal mining is related to strata breaking. The key strata location affects $H_{\mathrm{WFZ}}$ in the roof; when the distance from the key strata to the coal seam is less than a critical 
value, the fracture of key strata will develop to water-flowing fracture, and the same goes to the fracture of the overburden strata controlled by key strata leading to a synchronous breakage with key strata. A theoretical method to predict $H_{\mathrm{WFZ}}$ by the location of key strata was proposed. However, because of the complexity of strata structure, the methods are no longer applicable when the main key strata are less than a certain distance from the coal seam.

Similar simulation and numerical simulation are commonly adopted methods to evaluate mining-induced fracture in the coal mining industry of China. Similar simulation constructs the strata structure according to the similarity theory from various materials (sand, gypsum, lime, etc.) to derive the strata movement and the governing law of mining-induced fracture evolution [11]. In similar simulation, there are many factors affecting the experiment, such as material ratio, model humidity, and boundary loading, and both fracture development and strata failure are observed directly when excavation is simulated with the model. Its results are influenced by the operation of the experimenter and often have too much error for studying $H_{\mathrm{WFZ}}$ quantitatively.

Numerical simulation indicates the failure of the overburden strata by evaluating the stress state of calculation units. Specifically, a series of governing equations (e.g., displacement-strain, strain-stress, and stres-strength) are approximated according to the elastic-plastic yield state of the calculation elements as the excavation is modeled [12]. Numerical simulation is fast and reproducible and obviates field work, as the needed rock mechanics parameters are obtained from laboratory tests. Nevertheless, these parameters are mainly selected subjectively based on the experimenter's experience. Moreover, regarding the failure of coal and rock mass, the plastic yield in numerical simulation lacks appropriate physical meaning, and it is thus not clear how the mining fracture produced by plastic yield can be associated with the water conductivity of the WFZ for coal and rock mass in the plastic yield state.

In engineering practice, researchers mostly use one or more of the above methods to study the damage of overburden strata caused by the coal mining and comprehensively determine $H_{\mathrm{WFZ}}$, which is from 6.5 to 50 times the mining height and is related to the lithology of the overburden strata. However, we find that the results of the above methods are correct for specific cases; if the geological and mining conditions (e.g., goaf size and coal seam burial depth) change, the results will not provide a correct reference. Therefore, with inspiration from the above problems, we realize that the initiation and expansion of mining-induced fractures are fundamentally driven by the movement and deformation of the overburden strata [13-16]; in this work, we determined the fracture initiation criterion and the propagation degree of mining-induced fracture by using the overburden movement and overburden deformation index and we revealed the fracture initiation mechanism of the overburden strata. In this way, we applied the probability integral method to the overburden strata movement to establish an analytical method for predicting mining-induced fracture. The results of the current work may have a considerable impact on coal mine safety production, as they not only provide theoretical guidance for predicting and preventing disasters such as mine water inrush but also offer a new methodology for investigating mining-related fractures (e.g., gas drainage in the fracture field of unloading rock mass and evaluation of protective layer mining).

\section{Conceptualization}

In mining research, the overburden strata are segmented into the caving zone, the fracture zone, and the continuous deformation zone. The caving zone and the fracture zone are collectively referred to as the WFZ because they allow water from the surface or the aquifer to pass through. For any given overburden strata, $H_{\mathrm{WFZ}}$ is key to studying mininginduced fracture.

Under the influence of mining, the original fractures or the pore fractures (e.g., micropores and microcracks in the rock mass, large-scale fractures, joints, and fracture structures) expand and connect with each other to form complex mining fractures [17]. In panel advancing, the overlying strata undergo loading, unloading, and stress recovery, and the mechanism of fracture propagation involves shear and/ or tensile stress [18]. For unloading, the fracture surface is mainly tensile when the confining pressure is small, and shear fracture surfaces become increasingly dominant as the confining pressure rises [19].

The overburden strata are bent after mining the lower coal, and upon rupture, deformation of the strata propagates from the bottom to top. The deformation and failure laws underlying the mechanical behavior of the rock mass are complex. The strata within the rock mass experience horizontal tensile deformation during mining. Figure 1 illustrates the subsidence and the horizontal deformation of a strata layer above the panel.

In Figure 1, the strata layer outside the inflection point (the side of the coal wall) has a positive horizontal deformation. In other words, the strata layer in this region is subject to tensile deformation. When the tensile deformation is large enough, cracks will be formed through the strata layer. Because of the difference in the settlement curve of the adjacent strata, bedded fractures will be formed in the direction perpendicular to the bedding layer when vertical tension develops between adjacent strata. In the vicinity of the coal wall, the subsidence curve of the strata changes violently and separation cracks are easily formed, thus creating water channels in the layer. The interlayer penetrative fractures will jointly form a WFZ that can seriously threaten the safe operation of the panel [20].

Since many differences exist in the mechanical mechanism and response under different stress path conditions, it is inadequate to assess the fracture of rock mass only from the stress field changes in the mining-induced overburden. Layered and continuous structures exist in the strata of both the WFZ and the complete subsidence zone [1], and the irregularly developed fractures in the horizontal direction of the rock strata can be regarded as the tensile deformation of rock strata after mining. Thus, the horizontal deformation of the strata, which is the main underlying driver of fractures, can be used to quantify the initiation and propagation of cracks. 


\section{Mathematical Derivations}

For two-dimensional deformation (Figure 2), the subsidence, inclination, and curvature of the surface and the overburden strata can be calculated by probability integral functions. The horizontal deformation $(\varepsilon)$ is defined as the rate of the horizontal displacement of two given points ( $\mathrm{A}$ and $\mathrm{B}$ ) to their original distance, and the line deformation $\left(\varepsilon_{s}\right)$ is defined as the rate of the distance between $A$ and $B$ on the deformed surface (the arc length can be readily obtained by integration) to their original distance. The movement and deformation of subsurface and strata mainly depend on the horizontal movement coefficient $(b)$, whose variation in the overburden strata remains in controversy due to limited research data and the complex movements involved [21].

The surface of the strata to be calculated can be regarded as a plane with zero thickness, and the movement of the strata can be simplified as the surface deformation of an elastic plate. We assume that the strata will form a curved surface upon moving, and the curved surface only has a vertical displacement $w$, and no deformation occurs in $x$ and $y$ directions (Figure 3).

In Figure 3, the microelement at $(x, y)$ on the surface of the layer originally has an area of $S=\mathrm{d} x \mathrm{~d} y$. Under the influence of mining, the microelement then has a new area of $S^{\prime}$ that can be calculated from the surface subsidence function $w(x, y)$ as [22]

$$
S^{\prime}=\sqrt{1+\left(\frac{\partial w(x, y)}{\partial x}\right)^{2}+\left(\frac{\partial w(x, y)}{\partial y}\right)^{2}} \mathrm{~d} x \mathrm{~d} y
$$

In Figure 3, horizontal deformation is relatively large along the edge of the sinking basin, and fractures running through (vertical or oblique) the strata will be formed when the strata are stretched to a certain level. The horizontal deformation can be derived from the change of the strata surface. Specifically, the layer tensile rate of the mininginduced strata, denoted by $\varepsilon_{S}$, is the rate of the increment of curved surface area and the total area of the strata after deformation, which can be derived from the subsidence function of rock layer $w(x, y, z)$ :

$$
\begin{aligned}
\varepsilon_{S} & =\frac{\sqrt{1+(\partial w(x, y, z) / \partial x)^{2}+(\partial w(x, y, z) / \partial y)^{2}} \mathrm{~d} x \mathrm{~d} y-\mathrm{d} x \mathrm{~d} y}{\sqrt{1+(\partial w(x, y, z) / \partial x)^{2}+(\partial w(x, y, z) / \partial y)^{2}} \mathrm{~d} x \mathrm{~d} y} \\
& =1-\left[1+\left(\frac{\partial w(x, y, z)}{\partial x}\right)^{2}+\left(\frac{\partial w w(x, y, z)}{\partial y}\right)^{2}\right]^{-0.5},
\end{aligned}
$$

where $w(x, y, z)$ is the subsidence function of the strata layer $z$ at the depth above the coal seam.

In calculating the overburden strata movement, the strata movement and subsidence are inseparable [23-26]. Therefore, the changes of three parameters of the overburden must be taken into account, namely, the subsidence coefficient $q_{\mathrm{z}}$, the main influence radius $r_{\mathrm{z}}$, and the inflection point offset $s_{\mathrm{z}}$.
For half-infinite exploitation in the major cross section along the $x$ direction, the strata subsidence at a given burial depth of $z$ is [27]

$$
w(x, z)=\frac{W_{z}^{\max }}{\sqrt{\pi}} \int_{-\sqrt{\pi} x_{z} / r_{z}}^{\infty} e^{-\lambda^{2}} d \lambda=\frac{W_{z}^{\max }}{2}\left\{\operatorname{erf}\left[\frac{\sqrt{\pi}}{r_{z}}\left(x_{z}-s_{z}\right)\right]+1\right\},
$$

where $x_{z}$ is the horizontal distance from the calculated point to the mining boundary, $s z$ is the main influence radius of the strata formation, $s z$ is the displacement of the inflection point, and $W_{z}^{\max }$ is the maximum subsidence of the strata that equals $M \cdot q(z)$, in which $M$ is the mining height and $q(z)$ is the subsidence coefficient of the strata at burial depth $z$.

In equation (3), there are three parameters of strata movement at a burial depth of $z$, i.e., $W_{z}^{\max }, r_{\mathrm{z}}$, and $s_{\mathrm{z}}$. The functional relation of these parameters to the burial depth $z$ can be obtained as follows [28]:

$$
\begin{aligned}
& r_{z}=R\left(\frac{H_{0}-z}{H_{0}}\right)^{n_{r}}, \\
& q_{z}=1-\left(\frac{H_{0}-z}{H_{0}}\right)^{n_{q}}\left(1-q_{0}\right), \\
& s_{z}=s_{0}\left(\frac{H_{0}-z}{H_{0}}\right)^{n_{s}},
\end{aligned}
$$

where $H_{0}$ is burial depth of the coal seam, $z$ is the strata burial depth, $R$ is the main influence radius of the subsidence basin $\left(R=H_{0} \tan \beta\right.$ if the propagation angle of mining influence is $\beta), q_{0}$ is the subsidence coefficient of the surface subsidence basin, $s_{0}$ is the displacement of the inflection point on the surface subsidence basin, and $n_{r}, n_{q}$, and $n_{s}$ are the radius index, the subsidence coefficient index, and the inflection point offset index, respectively.

By substituting equations (4)-(6) into equation (3), the subsidence curve $w(x, z)$ of the strata at a burial depth of $z$ in the major cross section along the $x$-axis can be obtained. Thus, with regard to mining in the $3 \mathrm{D}$ space, the subsidence of any point $(x, y, z)$ in the strata can be obtained by superposing the subsidence curves of two perpendicular sections on each other:

$$
w(x, y, z)=\frac{1}{W_{z}^{\max }}\left[w(x, z)-w\left(x-l_{1}, z\right)\right]\left[w(y, z)-w\left(y-l_{2}, z\right)\right]
$$

where $l_{1}$ and $l_{2}$ are the mining size of the panel in the strike and dip directions, respectively.

Among the engineering and geological conditions that need to be considered to solve (7), $n_{r}, n_{q}$, and $n_{s}$ are mainly related to the structural characteristics of overburden strata. Fracture running through the strata will be formed under tensile stress only when the layer tensile rate of the strata reaches a certain level in the subsidence surface. In this way, the critical layer tensile rate $\varepsilon^{\prime}{ }_{S}$ can be used to characterize the layer tensile rate $\varepsilon_{S}$ when the water-flowing fractures are formed. An analytical model based on the above rationales can then be streamlined as follows: 


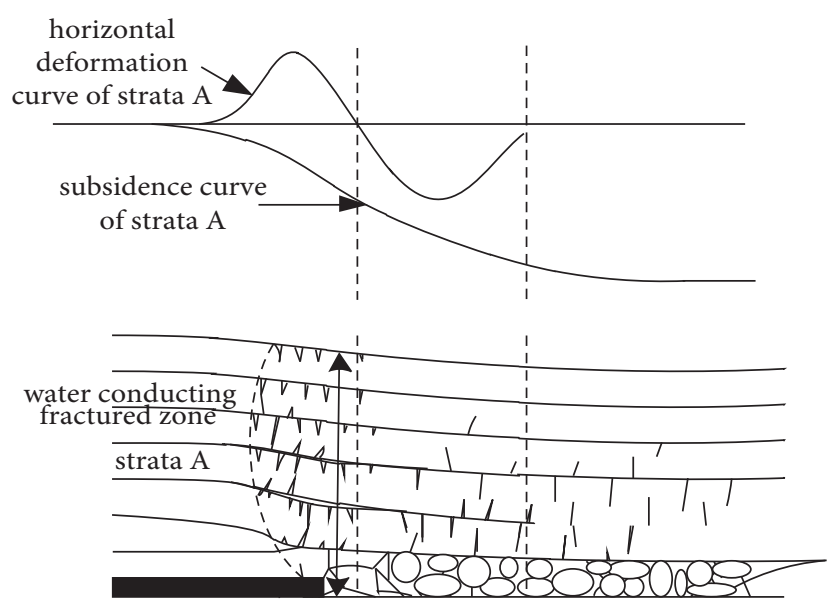

FIgURE 1: The relationship between the fracture and the deformation of strata.

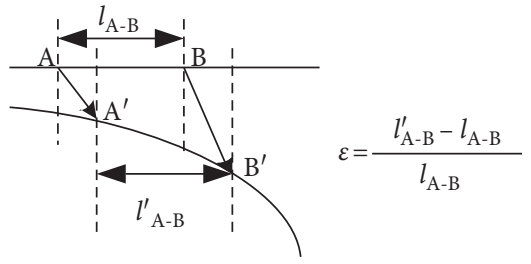

(a)

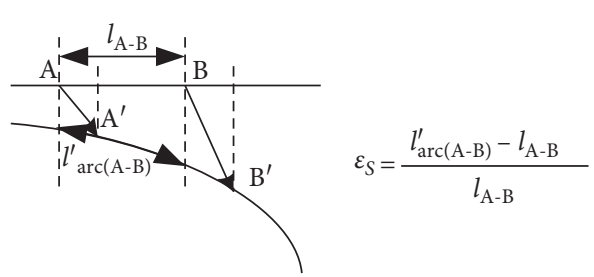

(b)

Figure 2: Definition of horizontal deformation and line deformation. (a) Horizontal deformation and (b) line deformation of line segment.

(1) Obtain the surface movement parameters of the coal mine and establish the probability integral function of overburden strata movement

(2) Substitute the probability integral function into equation (7) to obtain the layer tensile rate distribution

(3) Determine the critical layer tensile rate for fracture initiation

(4) Substitute the critical layer tensile rate into the distribution map of the strata layer tensile rate to determine the corresponding strata horizon and calculate $H_{\mathrm{WFZ}}$

\section{A Case Study: The Peigou Coal Mine}

4.1. Probability Integral Function of Overburden Strata Movement. The panel 31071 at the Peigou coal mine serves as an example. The average mined thickness is $7.5 \mathrm{~m}$, the dip of the coal seam is $15^{\circ}$, the length of the panel is $1100 \mathrm{~m}$, the dip length is $130 \mathrm{~m}$, and the vertical depth of the coal seam is $300 \mathrm{~m}$ below ground, and the mining method is fully mechanized top-coal caving. Because the panel is underneath the Modongwang reservoir on the surface, the risk of water inrush is high. The panel 31071 is used as the trial mining face of the mining area 31 . Before the panel mining, observation lines in the strike and the trend directions are arranged on the surface above the panel (Figure 4), and 23 measurements of surface movement are made. The measured data are used to derive the parameters needed in the probability integral function (Table 1).

According to [28], the radius index $n_{r}$ can be determined based on the bending stiffness distribution law as

$$
n_{r}=1.00\left(\frac{H_{0}-z}{H_{0}}\right)^{2}-\left(\frac{H_{0}-z}{H_{0}}\right)+0.5 .
$$

The subsidence coefficient index $n_{q}$ and the inflection point offset index $n_{s}$ are calculated by power functions to be 0.470 and 0.338 , respectively. With the mining area in strike and trend directions being $800 \mathrm{~m}$ and $130 \mathrm{~m}$, respectively, the subsidence functions of the overburden strata with different burial depth are then calculated. Figure 5 shows the major cross section of subsidence along the dip at a burial depth of $50,100,150,200,250$, and $270 \mathrm{~m}$, respectively.

4.2. Determination of the Layer Tensile Rate. The layer tensile rate $\varepsilon_{S}$ reflects the hydraulic conductivity and the expansion degree of mining-induced fractures, and it depends heavily on the lithology of the particular strata. The critical layer tensile rate $\varepsilon^{\prime}{ }_{S}$ characterizes the initiation of fractures under different mining conditions. The roof inclined borehole is constructed in the floor drainage roadway of panel 31131 before mining influence, and the borehole wall fracture pictures are obtained by borehole television. According to the borehole wall fracture, the mining-induced fracture density of the strata at $75 \mathrm{~m}$ above coal seam is significantly reduced after mining, and $H_{\mathrm{WFZ}}$ is 8.6 times the mining 


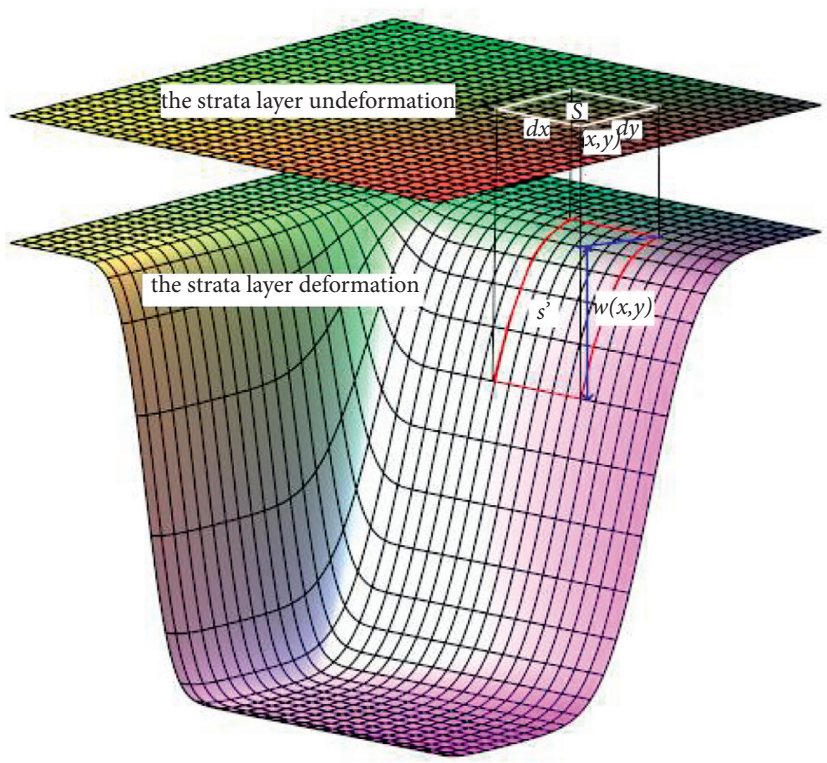

FIGURE 3: Schematic of a microcell in strata deformation.
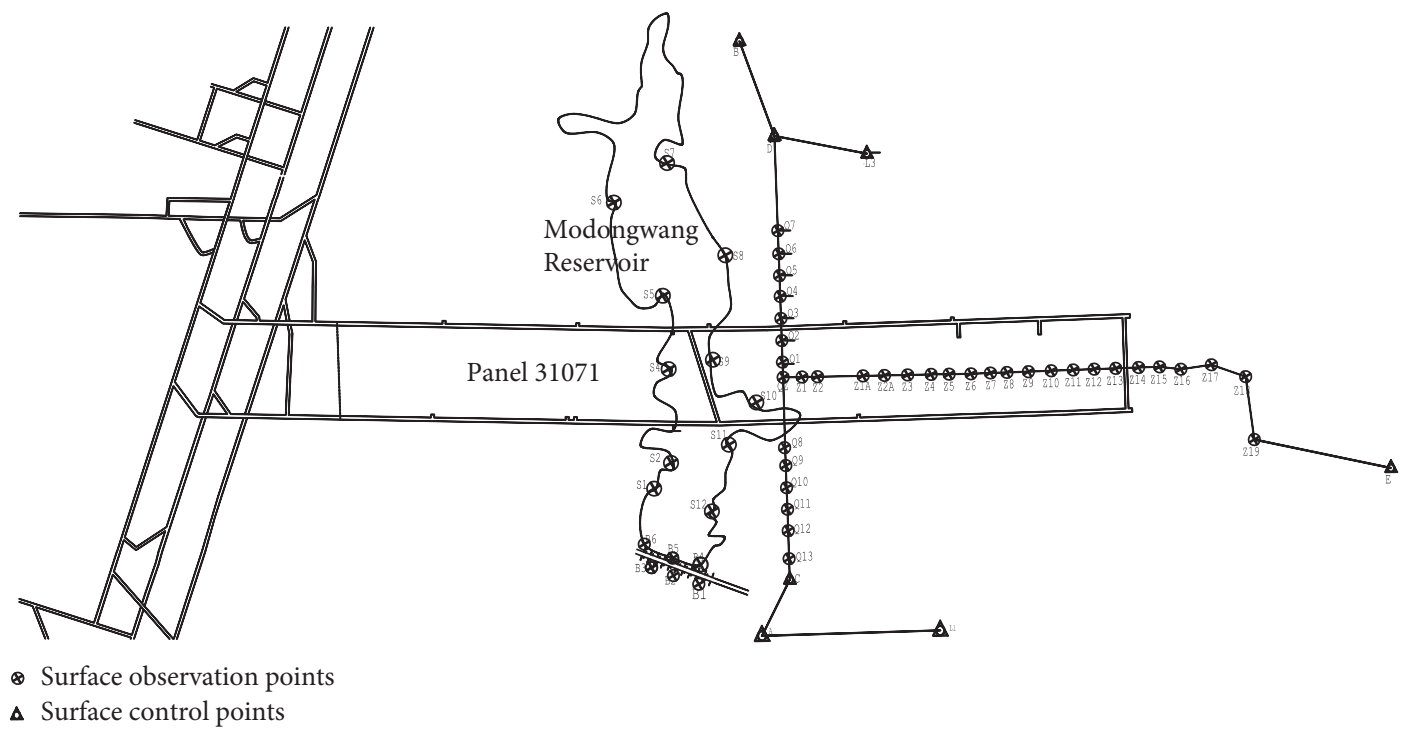

FIGURE 4: Location of observation stations.

height. With this information, we can substitute (7) into (2) to derive the distribution of the layer tensile rate and determine the top boundary of the WFZ (Figure 6), through which we find that the critical layer tensile rate $\varepsilon_{S}^{\prime}$ of the strata at the top boundary of the WFZ is $0.28 \%$.

4.3. Deriving $H_{W F Z}$ of the Panel 31071 . It can be seen from Figure 6 that the maximum value of the layer tensile rate of different strata on the uphill and downhill sides can be obtained in the major cross section along the dip. Therefore, the section at $400 \mathrm{~m}$ of mining distance is taken to calculate the distribution function of the layer tensile rate $\left.\varepsilon_{S}(h)\right|_{x=400}$ at different burial depths. Figure 7 shows the location of the top interfacial strata formation in the
WFZ, for which $\varepsilon^{\prime}$ S is calculated by the surface probability integral function based on the mining parameters of the panel 31071.

The red surface in Figure 7 denotes the critical layer tensile rate $\varepsilon^{\prime}$. From its intersections with the surface of the distribution function, $H_{\mathrm{WFZ}}$ on the uphill side and the downhill side can be determined, as plotted in Figure 8 . $H_{\text {WFZ }}$ is found to be 83.5 and $68.4 \mathrm{~m}$ on the uphill and the downhill side, respectively, for inclined coal seam mining in the panel 31071.

$H_{\mathrm{WFZ}}$ on the uphill side is usually used to assess safety in inclined coal seam mining to judge if water from the surface or from aquifers will pass through the WFZ to the goaf. Hence, $H_{\mathrm{WFZ}}$ in the panel 31071 is deemed $68.4 \mathrm{~m}$. According to the overburden strata information, the top 
TABLE 1: Data collected to set the parameters of the probability integral function.

\begin{tabular}{|c|c|c|c|c|c|c|}
\hline \multirow[t]{2}{*}{$\begin{array}{l}\text { Position of major cross } \\
\text { section }\end{array}$} & \multirow[t]{2}{*}{$\begin{array}{c}\text { Subsidence coefficient } \\
q_{0}\end{array}$} & \multicolumn{2}{|c|}{$\begin{array}{l}\text { The tangent of the } \\
\text { main influence } \\
\text { angle } \tan \beta\end{array}$} & \multicolumn{2}{|c|}{$\begin{array}{l}\text { Inflection point offset } \\
\qquad S_{0}(\mathrm{~m})\end{array}$} & \multirow[t]{2}{*}{$\begin{array}{l}\text { Mining influence transmission angle } \\
\qquad \theta_{0}\end{array}$} \\
\hline & & Downhill & Uphill & Downhill $s_{1}$ & Uphill $s_{2}$ & \\
\hline Dip & 0.80 & 2.43 & 2.30 & $0.14 H_{1}$ & $0.13 \mathrm{H}_{2}$ & $78.75^{\circ}$ \\
\hline Strike & 0.80 & 1.88 & $0.15 H_{0}$ & & & \\
\hline
\end{tabular}

$H_{1}$ and $H_{2}$ are the buried depth of coal seam at the boundary of downhill and uphill in dip direction.

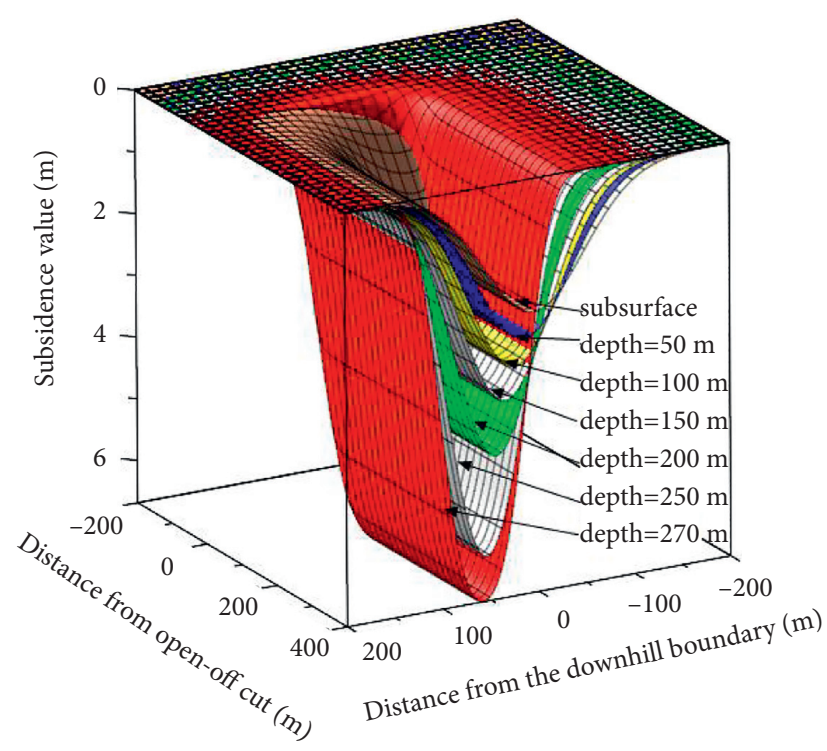

Figure 5: Subsidence induced by mining at the panel 31071.

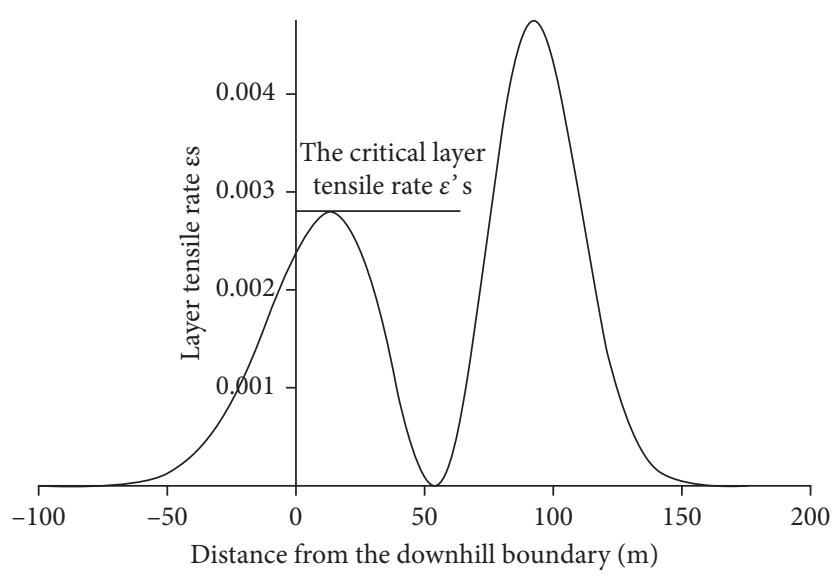

FIgURE 6: Critical layer tensile rate for the WFZ in the dip direction.

boundary strata in the WFZ are medium-grained sandstone and the safe distance between the strata and the surface should be $211.6 \mathrm{~m}$.

4.4. The Development of WFZ in the Overburden Strata. According to the above $H_{\mathrm{WFZ}}$ of the panel 31071, the WFZ is from the subsurface to $211.6 \mathrm{~m}$ below, in which there are a large number of argillaceous strata that can prevent the surface water from entering the panel. In actual operations, it was found that the water level of Modongwang reservoir remained largely stable after the panel has been mined, with a roof water inflow at $70 \mathrm{~m}^{3} / \mathrm{h}$ during the mining as is observed at the underground hydrological measuring stations.

The development of the WFZ upon further mining the coal seams was then explored. The panels 31051 and 31031 will be mined (Figure 9). Therefore, the development of the 


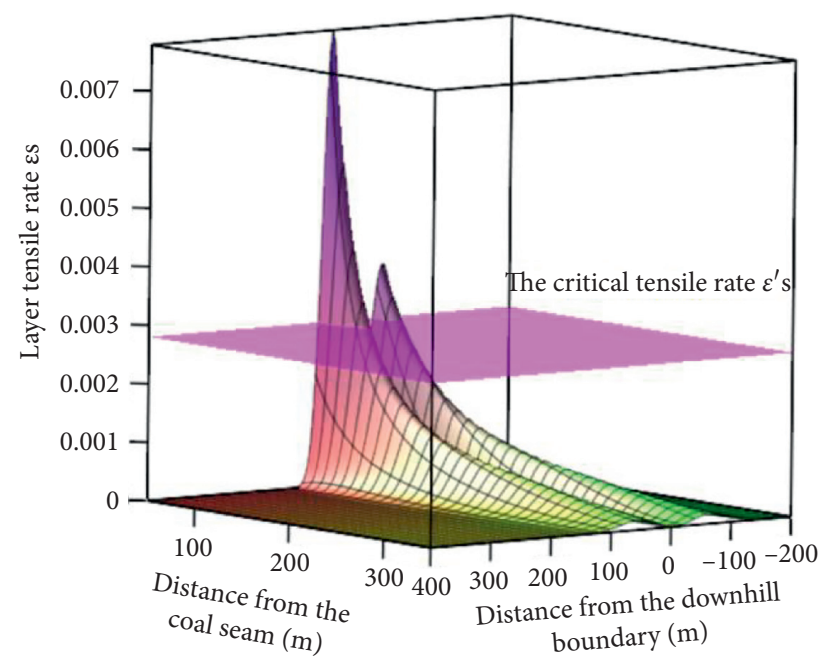

Figure 7: Surface of layer tensile rate and its critical value.

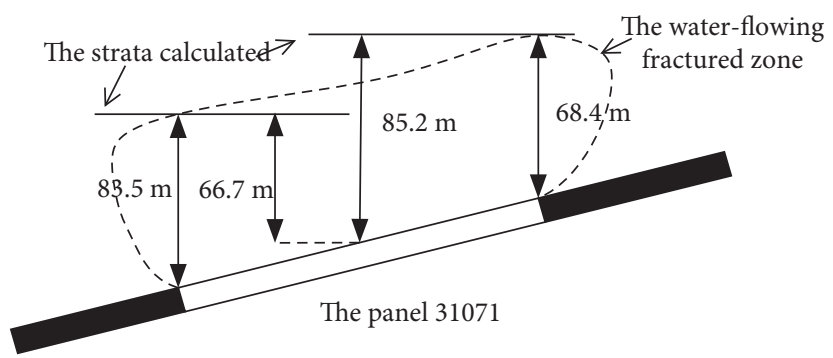

FIGURE 8: Height of the fractured zone in the panel 31071.

WFZ at subsequent stages of mining is then calculated. The mining width is $260 \mathrm{~m}$ and $390 \mathrm{~m}$ for Scheme 2 and Scheme 3 , respectively. Equation (2) is used to obtain the distribution function of the layer tensile rate, and $H_{\mathrm{WFZ}}$ is determined from the $\varepsilon^{\prime}$ S value (Figure 10).

With a critical layer tensile rate $\varepsilon^{\prime}$ S of $0.28 \%$, the distance between the coal seam level and the calculated strata is $132.8 \mathrm{~m}$ and $191.3 \mathrm{~m}$ for Scheme 2 and Scheme 3, respectively, and the corresponding $H_{\mathrm{WFZ}}$ is $99.2 \mathrm{~m}$ and $140.8 \mathrm{~m}$ (Figure 10). The impact of mining on the overburden strata depends on the size of the mining space, and the range overburden failure increases as the mining size of inclined panel grows. When the mining distance along dip increases from $130 \mathrm{~m}$ in Scheme 1 to $390 \mathrm{~m}$ in Scheme $3, H_{\mathrm{WFZ}}$ grows from $68.4 \mathrm{~m}$ to $140.8 \mathrm{~m}$, and then the lower boundary of the WFZ will be only $75.1 \mathrm{~m}$ underneath the surface. As there are thick mudstone and sandy mudstone over WFZ, the WFZ can still isolate the hydraulic communication between the surface water and the goaf, and the mining operation of the panel operation should remain safe.

For the sake of comparison, the empirical method was also used to assess the development of the WFZ. The overburden strata over the panel 31071 are mainly composed of medium and fine-grained sandstone, sandy mudstone, mudstone, and other rocks, and the layer of sandy mudstone and mudstone accounts for $58 \%$ of the total thickness of overburden strata. The comprehensive evaluation coefficient of the overburden strata has $P=0.56$ according to [29], and the lithology of overburden strata at the Peigou mine is hard. Therefore, $H_{\mathrm{WFZ}}$ for medium-hard lithology can be calculated as

$$
\begin{aligned}
& H_{\mathrm{WFZ}}=\frac{100 \sum M}{1.6 \sum M+3.6} \pm 5.6, \\
& H_{\mathrm{WFZ}}=20 \sqrt{\sum M}+10,
\end{aligned}
$$

where $M$ is the cumulative mining height.

For equations (9) and (10) to be applicable, the singlelayer mining height must be $<3 \mathrm{~m}$ and the accumulated mining height must be $<15 \mathrm{~m}$. The error term in (9) is denoted with a plus sign because the mining-induced influence is larger in fully mechanized top-coal caving mining than in single-layer mining. Table 2 compares the calculation results of the WFZ.

Table 2 shows that the results of equations (9) and (10) are not remarkably different from the results of the new method in Scheme 1, but the deviation steadily increases after mining is finished in the panel 31071 and proceeds into Schemes 2 and 3. For inclined coal seams, as mining advances, the mining size in the dip direction gradually increases and the burial depth of the coal seam gradually 


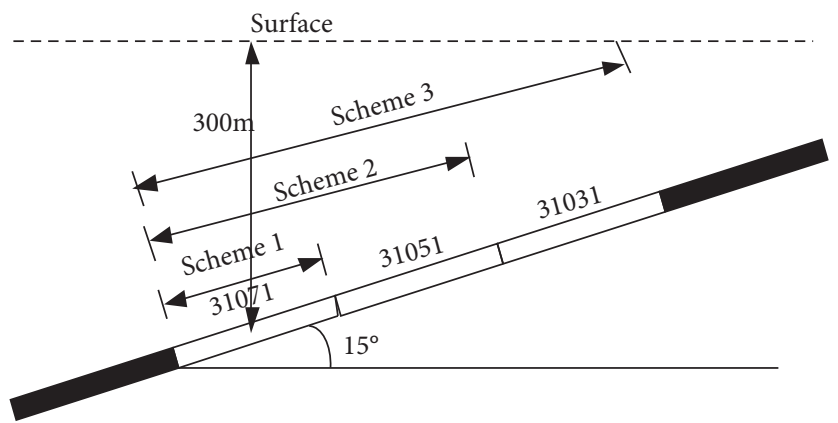

FIgURE 9: The mining schemes and the location of the panels.

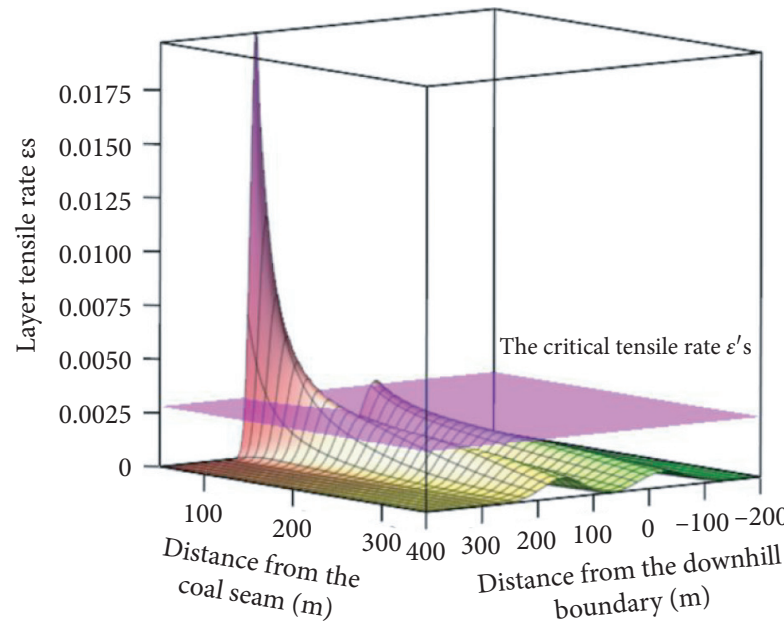

(a)

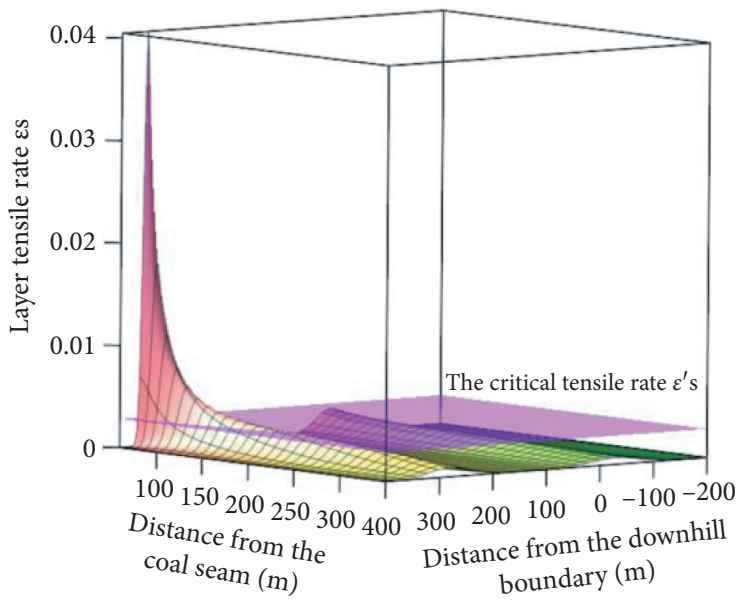

(b)

Figure 10: Calculated $H_{\mathrm{WFZ}}$ of major cross sections in the dip direction. (a) Scheme 2. (b) Scheme 3.

TABle 2: Calculation of $H_{\mathrm{WFZ}}$ by different methods.

\begin{tabular}{lccccc}
\hline \multirow{2}{*}{ Mining scheme } & \multirow{2}{*}{ Proposed method in paper (m) } & \multicolumn{2}{c}{ Traditional methods (m) } & \multicolumn{2}{c}{ Error rate (\%) } \\
& & Equation (9) & Equation (10) & Equation (9) & Equation (10) \\
\hline Scheme 1 & 68.4 & 53.68 & 64.78 & 21.52 & 5.29 \\
Scheme 2 & 99.2 & 53.68 & 64.78 & 45.89 & 34.70 \\
Scheme 3 & 140.8 & 53.68 & 64.78 & 61.88 & 53.99 \\
\hline
\end{tabular}

decreases. As a result, the movement and deformation of the overburden strata are inevitably magnified, and $H_{\mathrm{WFZ}}$ will grow accordingly. Unfortunately, conventional empirical methods do not reveal the development of the WFZ along with the progress of mining because they only consider the coal seam mining height $M$ in their prediction. Consequently, their predicted $H_{\mathrm{WFZ}}$ remains unchanged in different schemes, which fails to truly reflect the reality.

\section{Conclusions}

A new method is proposed for calculating the height of the water-flowing fractured zone, and a case study of Peigou mine is analyzed by the proposed method. The following conclusions are drawn:
(1) An analytical method is developed to determine $H_{\mathrm{WFZ}}$ of overburden strata by using probability integral function. In the developed method, the layer tensile rate of the neutral plane of the elastic plate characterizes the horizontal deformation of the strata in examining the initiation and expansion of mining fractures.

(2) As a important parameter in the proposed calculation method, the critical layer tensile rate $\varepsilon^{\prime}{ }_{S}(0.28 \%)$ is determined with the observation results of WFZ in the panel 31131 ; as an example, $H_{\mathrm{WFZ}}$ in the panel 31071 is deemed $68.4 \mathrm{~m}$ by the proposed method.

(3) The development of WFZ in the Peigou mine is assessed to showcase the utility of the proposed method and demonstrate its advantage compared 
with conventional empirical methods. For inclined coal seam mining, as the goaf size grows and the depth of the coal seam increases, $H_{\mathrm{WFZ}}$ steadily increases from $68.4 \mathrm{~m}$ to $99.2 \mathrm{~m}$ and eventually attains $140.8 \mathrm{~m}$. In evaluating the WFZ, the developed method not only considers the mining height but also accounts for variables including mining size, coal seam burial depth, and coal seam dip angle. In this way, the proposed method can predict the development of the WFZ more reliably and has greater value in engineering applications.

\section{Data Availability}

The data used to support the findings of this study are available from the corresponding author upon request.

\section{Conflicts of Interest}

The authors declare that they have no conflicts of interest.

\section{Acknowledgments}

This study has been financially supported by the Regional First-Class Discipline of Ecology in Guizhou Province, National Natural Science Foundation of China (Grant no. 51974105), Fund Project of Guizhou Education Department (KY[2018]388), Fund Project of Bijie Science and Technology Bureau (G[2019]1), and Fund Project of Guizhou University of Engineering Science (G2018012).

\section{References}

[1] M. G. Qian and J. L. Xu, "Behaviors of strata movement in coal mining," Journal of China Society, vol. 44, no. 4, pp. 973-984, 2019.

[2] F. Du, K. Wang, X. Zhang, C. Xin, L. Shu, and G. Wang, "Experimental study of coal-gas outburst: insights from coalrock structure, gas pressure and adsorptivity," Natural Resources Research, vol. 29, no. 4, pp. 2481-2493, 2020.

[3] F. Du and K. Wang, "Unstable failure of gas-bearing coal-rock combination bodies: insights from physical experiments and numerical simulations," Process Safety and Environmental Protection, vol. 129, pp. 264-279, 2019.

[4] S. G. Wang, Y. J. Shen, and Q. Sun, "Scientific issues of coal detraction mining geological assurance and their technology expectations in ecologically fragile mining areas of Western China," Journal of Mining and Strata Control Engineering, vol. 2, no. 4, Article ID 43531, 2020.

[5] G. C. Feng, B. H. Xu, and D. Wang, "Features of overburden failure and water filling in coal mining with sub-level caving under Santaizi reservoir," Journal of Mining \& Safety Engineering, vol. 31, no. 1, pp. 108-114, 2013.

[6] B. B. Gao, Y. P. Liu, J. Y. Pan, and T. Yuan, "Detection and analysis of height of water flowing fractured zone in under water mining," Chinese Journal of Rock Mechanics and Engineering, vol. 33, no. S1, pp. 3384-3390, 2014.

[7] Y. J. Sun, Z. M. Xu, and Q. H. Dong, "Monitoring and simulation research on development of water flowing fractures for coal mining under Xiaolangdi reservoir," Chinese Journal of Rock Mechanics and Engineering, vol. 28, no. 2, pp. 238-245, 2009.
[8] X. J. Hu, W. P. Li, D. T. Cao, and M. C. Liu, "Index of multiple factors and expected height of fully mechanized water flowing fractured zone," Rock Mechanics and Rock Engineering, vol. 37, no. 4, pp. 613-620, 2012.

[9] G. Jian and J. Ning, "Mechanical mechanism of overlying strata breaking and development of fractured zone during close-distance coal seam group mining," International Journal of Mining Science and Technology, vol. 30, no. 2, pp. 68-76, 2020.

[10] G. S. H. Xu, S. H. J. Xu, and D. H. Li, "Safety research on mining under Zhaocheng reservoir," Safety In Coal Mines, vol. 44, no. 4, pp. 43-45, 2013.

[11] X. Wu, X. G. Wang, and Q. W. Duan, "Numerical simulation of development height of water flowing fractured zone," Journal of China Coal Society, vol. 33, no. 6, pp. 11-14, 2008.

[12] W. Guo, G. Zhao, G. Lou, and S. Wang, "A new method of predicting the height of the fractured water-conducting zone due to high-intensity longwall coal mining in China," Rock Mechanics and Rock Engineering, vol. 52, no. 8, pp. 27892802, 2019.

[13] W. Gale, "Review and estimation of the hydraulic conductivity of the overburden above longwall panels. Experience from Australia," in Proceedings of the 19th International Conference on Ground Control in Mining, pp. 1-8, West Virginia University, Morgantown, WV, USA, Jan 12010.

[14] Y. Luo and B. Qi, "Enhanced subsurface subsidence model prediction model that considers overburden stratification," International Journal of Mining Engineering, vol. 64, no. 10, pp. 78-84, 2014.

[15] Y. F. Gao, W. P. Huang, G. L. Liu, S. F. Zhang, Q. M. Zhu, and Z. Y. Deng, "The relationship between permeable fractured zone and rock stratum tensile deformation," Journal of Mining \& Safety Engineering, vol. 29, no. 3, pp. 301-306, 2012.

[16] B. C. Zhao, Z. G. Li, and Z. R. Tong, "Height of water flowing fractured zone and mining parameters," Journal of Mining \& Safety Engineering, vol. 32, no. 4, pp. 634-638, 2015.

[17] D. J. Xue, H. W. Zhou, C. S. Wang, and H. L. Gao, "Percolation model of mining-induced crack evolution of the overlying strata," Journal of China University of Mining \& Technology, vol. 42, no. 6, pp. 917-922, 2013.

[18] L. J. Chen, T. B. Li, G. Wang, and X. Wu, "Study on crack expansion judgment method in overlying strata and its application for coal mining under aquifers," Journal of China Coal Society, vol. 39, no. S2, pp. 301-307, 2014.

[19] J. H. Shen, L. S. Wang, Q. H. Wang, J. Xu, Y. Jiang, and B. Sun, "Deformation and fracture features of unloaded rock mass," Chinese Journal of Rock Mechanics and Engineering, vol. 22, no. 12, pp. 2028-2031, 2003.

[20] Y. J. Song, G. Q. Cheng, and W. J. Guo, "Study of distribution of overlying strata fissures and its porosity characteristic," Rock and Soil Mechanics, vol. 32, no. 2, pp. 533-536, 2011.

[21] L. Yang and H. Y. Dai, "Thoughts of calculation method of coal mining subsidence in home," Coal Mining Technology, vol. 102, no. 2, pp. 7-9, 2016.

[22] S. Wang, X. Li, and D. Wang, "Void fraction distribution in overburden disturbed by longwall mining of coal," Environmental Earth Sciences, vol. 75, no. 2, pp. 151-156, 2016.

[23] X. P. Li, H. M. Wang, and Y. Xu, "Parameter inversion of probability integration method using surface movement vector," Chinese Journal of Geotechnical Engineering, vol. 40, no. 4, pp. 767-776, 2018.

[24] S. J. Song, S. M. Wang, and X. G. Zhao, "Stratification transfer method of the mining subsidence based on the characteristics 
of layered structure in coal overburden," Rock and Soil Mechanics, vol. 37, no. 12, pp. 3387-3392, 2016.

[25] X. L. Yao, B. N. Whittaker, and D. J. Reddish, "Influence of overburden mass behavioural properties on subsidence limit characteristics," Mining Science and Technology, vol. 13, no. 2, pp. 167-173, 1991.

[26] C. O. Aksoy, H. Kose, T. Onargan, Y. Koca, and K. Heasley, "Estimation of limit angle using laminated displacement discontinuity analysis in the Soma coal field, Western Turkey," International Journal of Rock Mechanics and Mining Sciences, vol. 41, no. 4, pp. 547-556, 2004.

[27] X. Cui, J. Wang, and Y. Liu, "Prediction of progressive surface subsidence above longwall coal mining using a time function," International Journal of Rock Mechanics and Mining Sciences, vol. 38, no. 7, pp. 1057-1063, 2001.

[28] G. S. Xu, Mechanism and Prediction Model of Overlying Strata Movement and Deformation Based on the Stress Distribution, Henan Polytechnic University, Jiaozuo, China, 2017.

[29] The State Administration of Work Safety, Code for Retaining Coal Pillars in Buildings, Water Bodies, Railways and Main Shafts and Roadways and Mining of Pressed Coal, China Coal Industry Publishing home, Beijing, China, 2017. 